\title{
RESPOSTA DA CULTURA DO MILHO À ADUBAÇÃO ORGANOMINERAL E ADUBAÇÃO QUÍMICA
}

\author{
Lucas Possamai $^{1}$ \\ ${ }^{1}$ Engenheiro Agrônomo, Especialista em Fertilidade do solo e Nutrição de Plantas. \\ Email: lucas.possamai@hotmail.com
}

RESUMO: O presente trabalho teve como objetivo avaliar a produtividade e alguns caracteres agronômicos da cultura do milho sobre a adubação organomineral e a adubação química onde ambas as formulações se equivalem segundo empresa fornecedora do adubo organomineral. $\mathrm{O}$ experimento foi conduzido no município de Itaipulândia - PR. O delineamento foi em DBC, compostos por três tratamentos e sete repetições de cada tratamento: Tratamento 1 - Sem Adubação; Tratamento 2 - adubo químico na base recomendado + ureia; Tratamento 3 - adubo organomineral na base recomendado + ureia. $\mathrm{Na}$ adubação de base foram utilizados adubos equivalentes segundo fabricante do fertilizante organomineral, $300 \mathrm{~kg} \mathrm{ha}^{-1}$ do adubo químico formulado $10-15$ - 15, e $300 \mathrm{~kg}$ $\mathrm{ha}^{-1}$ do adubo organomineral da formulado 05-10-10. Os resultados obtidos foram submetidos à análise de variância e as médias comparadas com o teste de Tukey a 5\% de probabilidade, utilizando o programa Sisvar. A adubação organomineral não traz resultados superiores a adubação química quando utilizadas formulações que se dizem equivalentes, neste trabalho as plantas com adubação química obtiveram maior estatura que os demais tratamentos e produziram em media $1368 \mathrm{~kg} \mathrm{ha}^{-1}$ a mais que a adubação organomineral, mostrando desta forma que a adubação química é mais vantajosa.

Palavras-chave: Adubação orgânica. Adubação de base. Zea mays.

\section{RESPONSE OF CULTURE MAIZE ON FERTILIZATION CHEMICAL AND ORGANIC-MINERAL}

\begin{abstract}
This study aimed to evaluate yield and some agronomic traits of corn on the organic mineral fertilizer and chemical fertilizer where both formulations are equivalent seconds vendor of organic-fertilizer. The experiment was conducted in the municipality of Itaipulândia- PR. The design was DBC, composed of three treatments and seven replicates of each treatment: Treatment 1 No-fertilization; Treatment 2 - chemical fertilizer + urea in the recommended base; Treatment 3 - organic mineral fertilizer at recommended + urea basis. On the basis of fertilization equivalent fertilizers were used according to manufacturer this fertilizer, $300 \mathrm{~kg} \mathrm{ha}^{-1}$ of chemical fertilizer formulated $10-15-15$ and $300 \mathrm{~kg} \mathrm{ha}^{-1} \mathrm{of}^{-}$ organic-fertilizer formulated $05 / 10 / 10$. The results were submitted to analysis of variance and means compared with the Tukey test at $5 \%$ probability using the Sisvar program. The organic-fertilizer does not bring better results than chemical fertilizer when used formulations that claim to be equivalent, in this study the plants with chemical fertilizer had higher stature than the other treatments and produced on average $1368 \mathrm{~kg} \mathrm{ha}^{-1}$ more than the
\end{abstract}


organic mineral fertilizer, showing this so that chemical fertilizer is more advantageous.

Key words: Organic manure. Chemical manure. Zea mays.

\section{INTRODUÇÃO}

O milho é um cereal que pertence à família das Poáceas, pode ser considerada uma das principais fontes de alimento atualmente, é utilizado tanto para a alimentação humana quanto animal (BORÉM; GIÚDICE, 2004). Antigamente o milho era relacionado à função de subsistência, hoje, sua produção é associada a cultivos comerciais baseado na utilização de tecnologias modernas (SOUZA; BRAGA, 2004). Segundo Coelho (2006) o milho é uma cultura que remove grandes quantidades de nitrogênio e usualmente requer o uso de adubação nitrogenada em cobertura para complementar a quantidade suprida pelo solo, quando se deseja produtividades elevadas. Os sistemas de produção agropecuários geram diversos resíduos orgânicos e sua utilização como fonte de nutrientes às plantas e condicionadores dos solos tem se constituído em uma opção interessante para a preservação da qualidade ambiental (MELLO; VITTI, 2002). De acordo com VEZZANI et al. (2008) o fertilizante orgânico eleva os teores de nitrogênio, fósforo e enxofre devido o processo de mineralização da matéria orgânica, promove a redução da fixação do fósforo pelos óxidos de ferro e alumínio (RHEINHEIMER et al., 2008).

Forma também quelatos solúveis de ferro, manganês, zinco e cobre, disponibilizando-os às raízes e favorece a atividade microbiológica e adição de novos microorganismos, diversificando a flora e a microflora do solo (ALLEONI; BEAUCLAIR, 1995). Tais fatores elevam a absorção de nutrientes pelas plantas, mostrando que os benefícios da adubação orgânica são inúmeros e em longo prazo, no decorrer dos anos, com vantagens econômicas futuras. Segundo Malavolta (1989), os adubos são capazes muitas vezes de quadruplicar a produção, é isso que o agricultor vem a cada dia querendo, um adubo que não apenas aumente essa produção, mas que também aumente o seu lucro. Segundo Büll (1993), entre as tecnologias disponíveis no meio agrícola, a adubação tem sido considerada a mais limitante para o aumento da produtividade das lavouras de milho. $\mathrm{O}$ objetivo principal deste trabalho foi avaliar a produtividade, comparando a adubação organomineral x adubação química, assim como avaliar alguns caracteres agronômicos como altura das plantas, número de grãos por fileira e numero de fileiras entre os tratamentos.

\section{MATERIAL E MÉTODOS}

O experimento foi conduzido no município de Itaipulândia-PR no ano de 2014 , apresentando as seguintes coordenadas latitude $25^{\circ} 10^{\prime} 58^{\prime}$ 'S e longitude $54^{\circ} 19^{\prime} 00^{\prime}$ ' O, com altitude de 275 metros. O solo da área experimental foi classificado como LATOSSOLO VERMELHO Distrófico típico (EMBRAPA, 2006).

A cultivar utilizada nesse trabalho foi SYN STATUS VIPTERA da empresa 
Syngenta, sendo considerado um milho de alto nível tecnológico e de alto potencial produtivo, classificada como uma cultivar precoce, uma boa sanidade foliar e um teto produtivo muito alto.

Tabela 1. Resultado da analise química do solo.

\begin{tabular}{|c|c|c|c|c|c|c|c|c|}
\hline \multicolumn{7}{|c|}{$\left(\mathrm{Mg} / \mathrm{dm}^{3}\right)$------- $\mathrm{Cmol}_{\mathrm{d}} / \mathrm{dm}^{3}$} & \multirow{2}{*}{$\begin{array}{c}\left(\mathrm{g} / \mathrm{dm}^{3}\right) \\
\mathrm{Mo}\end{array}$} & \multirow{2}{*}{$\begin{array}{l}\% \\
\mathrm{~V} \\
\end{array}$} \\
\hline $\mathrm{pH} \mathrm{CaCl}_{2}$ & $\mathrm{P}$ & $\mathrm{K}$ & $\mathrm{Ca}$ & $\mathrm{Mg}$ & $\mathrm{H}+\mathrm{Al}$ & CTC & & \\
\hline 5,6 & 15,12 & 0,41 & 7,50 & 2,24 & 5,54 & 15,47 & 34,98 & 71,47 \\
\hline
\end{tabular}

O delineamento foi utilizado em blocos casualizados com parcelas de 9 linhas espaçadas de $0,45 \mathrm{~m}$ entre si. Foi utilizado para avaliação apenas as 5 linhas do centro com $6 \mathrm{~m}$ de comprimento, sendo dessa forma a área 13,50 $\mathrm{m}^{2}$ por parcela. Os Tratamentos foram distribuídos na seguinte forma: Tratamento 1 - Sem aplicação de $\mathrm{N}$ na semeadura; Tratamento $2-300 \mathrm{~kg} \mathrm{ha}^{-1}$ do adubo químico formulado $10-15-15+$ ureia; Tratamento 3 - $300 \mathrm{~kg} \mathrm{ha}^{-1}$ do adubo organomineral formulado 05-10-10 + ureia, sendo ambos equivalentes segundo fabricante Fertilizante Minorgam do fertilizante organomineral, a divisão teve 3 tratamentos e 7 repetições, totalizando 21 parcelas. A dessecação pré-plantio foi realizada com glifosate, 20 dias antes da semeadura, o controle de plantas daninhas, e todos os tratos culturais foram feitos utilizando-se pulverizador tratorizado. A semeadura, em sistema plantio direto, foi realizada em 23 de março de 2014, de forma mecanizada utilizando- se semeadora da marca Baldan, modelo PPSOLO4000. A densidade usada foi de 2,5 sementes por metro e o espaçamento entre linhas foi $0,45 \mathrm{~m}$ a uma profundidade de 3 $\mathrm{cm}$, o poder germinativo mínimo das sementes eram de $85 \%$ e pureza mínima de $95 \%$.

A aplicação de $\mathrm{N}$ (ureia) foi realizada em cobertura após 40 dias da semeadura utilizando $60 \mathrm{~kg} \mathrm{ha}^{-1} \mathrm{e} \mathrm{N}$.

A produtividade foi obtida a partir das plantas da área útil das parcelas experimentais sendo as 5 linhas centrais de 6 metros de comprimento, totalizando uma área útil de 13,5 m². As quatro linhas externas de cada parcela e 1,0 m de cada extremidade foram consideradas como bordadura, minimizando desta forma os erros que podem aparecer, o milho foi colhido de forma manual, onde dentro dos $13,5 \mathrm{~m}^{2}$ da parcela foram retiradas amostras e os valores extrapolados para hectare.

Foram avaliados os componentes de produção: altura de plantas, numero de grãos por espiga, numero de fileiras de grãos e produtividade por ha, os resultados foram submetidos à análise de variância, e as médias comparadas pelo teste de Tukey a 5\% de probabilidade, através do pacote estatístico Sisvar.

\section{RESULTADOS E DISCUSSÃO}

Na Figura 1 pode-se observar que não houve diferença estatística entre a adubação química e a adubação organomineral, na variável número de grãos por fileira, mas ambas se diferem da testemunha. A contagem de numero de fileiras variou entre 16 grãos a 18 grãos em todos os tratamentos tendo sempre números pares e nunca impares. $\mathrm{T}_{1}, \mathrm{~T}_{2} \mathrm{e} \mathrm{T}_{3}$ tiveram os mesmos resultados não havendo variância. Já em trabalho de Silva et al. (2005)

Cultura Agronômica, Ilha Solteira, v.25, n.1, p.71-78, 2016 
estudando de doses de $\mathrm{N}$ em cobertura no milho, foi observado aumento do número de fileiras, grãos por fileira, grãos por espiga e massa de mil grãos com o aumento da dose de $\mathrm{N}$ na cultura. Esse resultado difere deste trabalho isto pode ter ocorrido devido a cama de aviário que foi utilizada no trabalho destes autores que pode ter fornecido vários nutrientes, com destaque para o $\mathrm{N}$. Pode-se dizer que as doses de $\mathrm{N}$ em conjunto com a adubação organomineral não trouxeram resultados similares aos obtidos no presente trabalho.

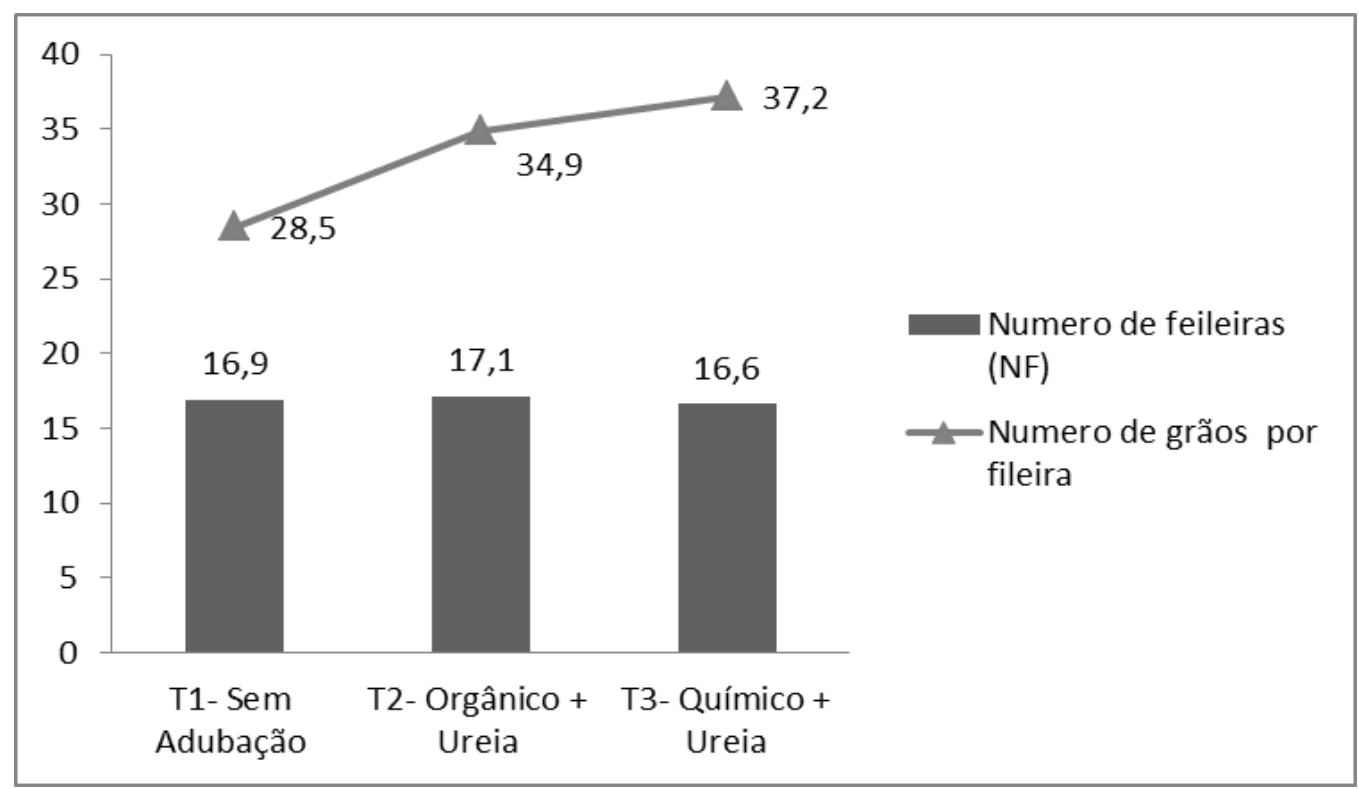

Figura 1. Número de Fileiras e número de grãos por fileira.

Na Figura 2 os tratamentos apresentaram diferença estatística sendo que o tratamento que obteve em média a maior estatura das plantas foi o $\mathrm{T}_{3}$ com adubação química e a menor média foi $\mathrm{T}_{1}$ sem o uso de adubação. Dania et al. (2012) verificaram que o fertilizante organomineral tem efeito benéfico no progresso do crescimento e na produtividade do milho cultivado em solo degradado onde a camada superior foi erodida, resultados estes que se mostraram diferentes em solos não degradados como o que foi realizado neste trabalho.

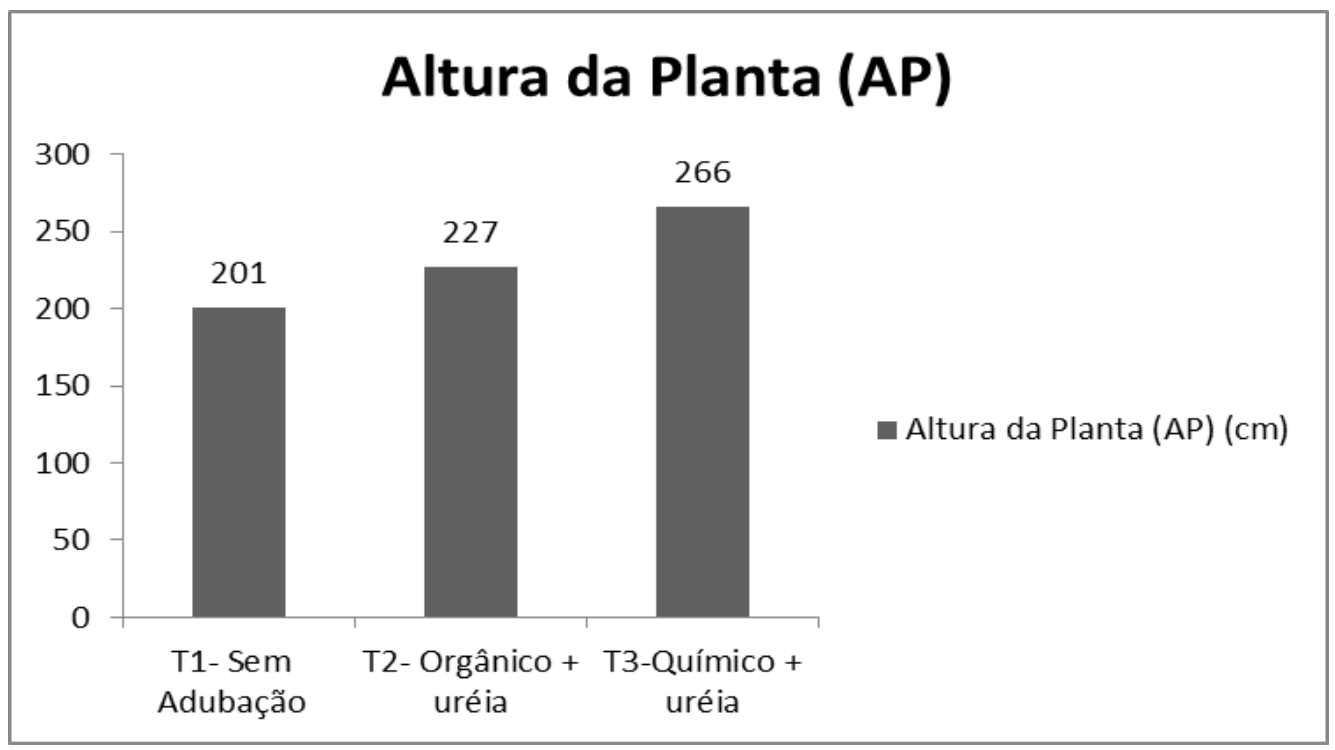

Figura 2. Diferença da altura da planta entre os tratamentos. $(\mathrm{cm})$.

Cultura Agronômica, Ilha Solteira, v.25, n.1, p.71-78, 2016 
Na Figura 3 pode-se observar que o Tratamento $T_{1}$ apresentou a menor media $T_{2}$ apresentou valor intermediário seguido da $\mathrm{T}_{3}$ que obteve a melhor media. A maior média difere em $3.567 \mathrm{~kg} \mathrm{ha}^{-1}$ da menor média. A aplicação de adubação mineral produziu em media cerca de 23 sacas a mais que o organomineral. Mas para BISSANI et al. (2004) somente com a utilização de adubo químico não é possível manter produtividade satisfatória por longo prazo, e que mesmo os adubos orgânicos apresentando baixas concentrações de $\mathrm{N}, \mathrm{P}$ e K quando complementados com adubação mineral, propiciam efeitos positivos às plantas, uma vez que estas aproveitam melhor os nutrientes através do sincronismo de liberação ao longo de seu desenvolvimento. A adição de resíduos orgânicos ao solo representa uma importante fonte de nutrientes às plantas, especialmente de nitrogênio $(\mathrm{N})$ e fósforo $(\mathrm{P})$, disponibilizados após a decomposição dos resíduos pela microbiota do solo (KIEHL, 1985).

O fertilizante orgânico aumenta os teores de nitrogênio, fósforo e enxofre devido o processo de mineralização da matéria orgânica (VEZZANI et al., 2008) e promove a redução da fixação do fósforo pelos óxidos de ferro e alumínio (RHEINHEIMER et al., 2008). Forma também quelatos solúveis de ferro, manganês, zinco e cobre, disponibilizando-os às raízes o que favorece a atividade microbiológica e adição de novos microorganismos, diversificando a flora e a microflora do solo (ALLEONI; BEAUCLAIR, 1995). Tais fatores elevam a absorção de nutrientes pelas plantas, mostrando que os benefícios da adubação orgânica são inúmeros e em longo prazo, no decorrer dos anos, com vantagens econômicas futuras.

Galvão (1998) destaca em um experimento realizado por vários anos na cultura do milho que o rendimento com composto orgânico foi de $6.500 \mathrm{~kg} \mathrm{ha}^{-1}$, e com adubação mineral a produção foi de $4.900 \mathrm{~kg} \mathrm{ha}^{-1}$, comprovando que o uso contínuo de composto orgânico melhorou a fertilidade do solo ao longo dos anos. Assim como Silva et al. (2007) que também verificaram que o uso contínuo de adubação organomineral na cultura do milho por vários anos provoca aumentos significativos na produção de grãos. Já Costa et al. (2011 a, b) comentam que não houve diferença entre a adubação mineral, orgânica e organomineral na produtividade do milho. Até o momento as informações disponíveis na literatura quanto ao uso associado de adubação orgânica com fertilizantes minerais na cultura do milho safrinha são incipientes e escassas. GOMES et al. (2005) também verificaram que a associação de resíduos orgânicos e fertilizante mineral, não influenciou a produtividade da cultura de milho. 


\section{Produtividade (PROD)}

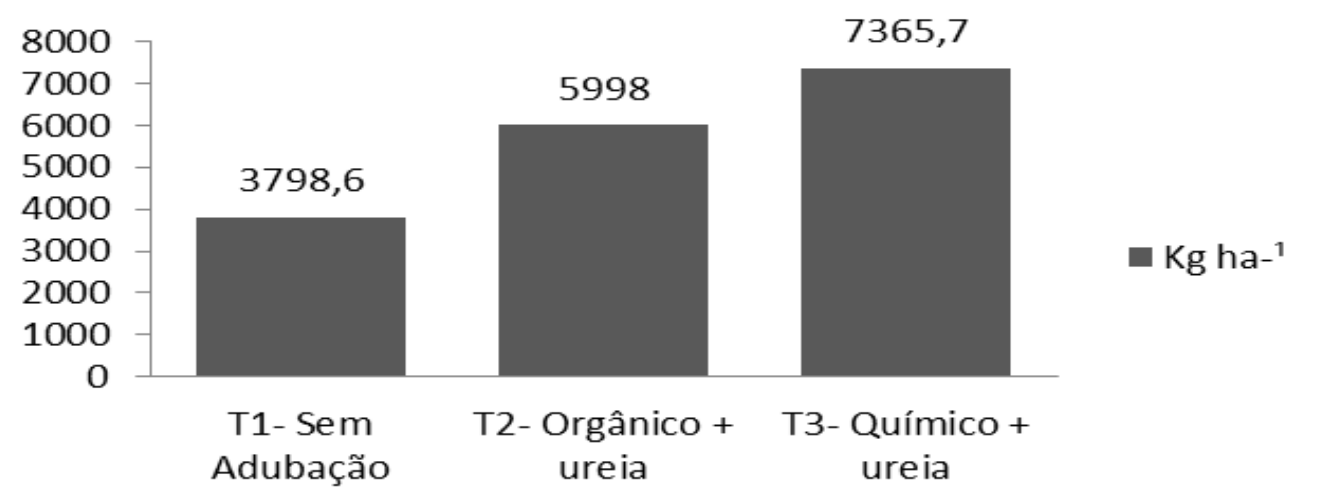

Figura 3. Produtividade de grãos entre os tratamentos.

O milho é uma das culturas mais importantes para a agricultura brasileira, devido à grande diversidade de épocas de cultivo, o mesmo permanece no campo durante praticamente todo o ano (SILVA; SCHIPANSKI, 2006).

No Brasil, o rendimento médio é ainda muito baixo quando comparado com resultados obtidos em outros países. Observando as melhores produtividades nas regiões Sul e Sudeste, responsáveis por mais de 90\% da produção total (FORNASIERI FILHO, 1992).

Os resultados mostrados neste trabalho são baseados em um ano, por isso alguns dos valores se diferem dos demais autores que mostram que com a utilização do fertilizante orgânico ou organomineral com uso continuo podem trazer melhores resultados.

\section{CONCLUSÃO}

Concluiu-se que, a adubação organomineral não traz resultados superiores a adubação química quando utilizadas formulações que se dizem equivalentes, neste trabalho as plantas com adubação química obtiveram maior estatura que os demais tratamentos e produziram em media $1368 \mathrm{~kg} \mathrm{ha}^{-1}$ mais que a adubação organomineral, mostrando desta forma que a adubação química é mais vantajosa que a adubação organomineral.

\section{REFERÊNCIAS BIBLIOGRÁFICAS}

ALLEONI, L.R.F.; BEAUCLAIR, E.G.F. Cana-de-açúcar cultivada após milho e amendoim, com diferentes doses de adubo. Scientia Agricola, Piracicaba, v. 52, n. 3, p.409415, 1995.

BISSANI, C. A.; GIANELlO, C.; TEDESCO, M. J.; CAMARGO, F. A. O. Fertilidade dos Solos e Manejo da Adubação de Culturas. Porto Alegre: Gênesis, 2004. 328 p.

BORÉM, A.; GIÚDICE, M. P. Cultivares transgênicos. In: GALVÃO, J. C. C.; MIRANDA, G. V. Tecnologias de Produção do Milho. 20. ed. Viçosa: UFV, 2004, v.1, p.85-108. 
BÜLL, L. T. Nutrição mineral do milho. In: BÜLL, L. T.; CANTARELLA, H. Cultura do Milho: fatores que afetam a produtividade. Piracicaba: Potafós, 1993. p. 147-196.

COELHO, M. A. Nutrição e adubação do milho. Sete Lagoas, MG: Ministério de Agricultura pecuária e abastecimento, 2006. Disponível em: http://www.cnpms.embrapa.br/publicacoes/publica/2006/circular/Circ_78.pdf. Acesso em: 24 set. 2014

COSTA, M. S. S. M.; PIVETTA, L. A.; COSTA, L. A. M.; PIVETTA, L. G.; CASTOLDI, G.; STEINER, F. Atributos físicos de solo e produtividade do Milho sob Sistemas de Manejo e adubações. Revista Brasileira de Engenharia Agrícola e Ambiental, Campina Grande, v. 15, n. 8, p.810-815, 2011a.

COSTA, M. S. S. M.; STEINER, F.; COSTA, L. A. M.; CASTOLDI, G.; PIVETTA, L. A. Nutrição e produtividade da Cultura do Milho em Sistemas de Culturas e Fontes de adubação. Revista Ceres, Viçosa, v. 58, n. 2, p.249-255, 2011 b.

DANIA, S. O.; FAGBOLA, O.; ISITEKHAL, H. H. E. Effects of sawdust and organomineral fertilizer and their residual effect on the yield of maize on degraded soil. Pakistan Journal of Agricultural Sciences, Paquistão, v. 49, n. 1, p.61-66, 2012.

EMBRAPA. Sistema brasileiro de classificação de solo. 2. ed. Rio de Janeiro: EMBRAPA Solos, 2006, p. 306.

FORNASIERI FILHO, D. Cultivares. In: A cultura do milho. Jaboticabal: FUNEP, 1992. cap. 4, p. 63-79.

GALVÃO, J. C. C. Adubação orgânica na cultura do milho. In: ENCONTRO MINEIRO SOBRE PRODUÇÃO ORGÂNICA DE HORTALIÇAS, 1., 1998, Viçosa. Anais. Viçosa: UFV, 1998. p 36-37.

GOMES, J. A.; SCAPIM, C. A.; BRACCINI, A. L.; VIDIGAL FILHO, O. S.; SAGRILO, E.; MORA, F. Adubações orgânica e mineral, produtividade do milho e características físicas e químicas de um Argissolo Vermelho Vermelho-Amarelo. Acta Scientiarum Agronomy, Maringá, v. 27, n. 3, p.521-529, 2005.

KIEHL, E. J. Fertilizantes orgânicos. São Paulo: Ceres, 1985. 482 p.

MALAVOLTA, E. ABC da Adubação. São Paulo: Ed. Ceres. 1989. 292 p.

MELLO, S. C.; VITTI, G. C. Desenvolvimento do tomateiro e modificações nas propriedades químicas do solo em função da aplicação de resíduos orgânicos, sob cultivo protegido. Horticultura Brasileira, Brasília, v. 20, n. 2, p.200-206, 2002.

PIRES, J. F.; JUNQUEIRA, A. M. R. Impacto da adubação orgânica na produtividade e qualidade das hortaliças. Horticultura Brasileira, Brasília, v. 19, n. 2, p.195, 2001.

RHEINHEIMER, D. S.; CASSOL, P. C.; KAMINSKI, J; ANGHINONI, I. In: SANTOS, G. A.; SIlVA, L. S.; CANELlAS, L. P.; CAMARGO, F. A. O. (Eds.). Fundamentos da matéria orgânica do solo: ecossistemas tropicais e subtropicais. 2 ed. Porto Alegre: Metrópole, 2008. p. 101-112.

Cultura Agronômica, Ilha Solteira, v.25, n.1, p.71-78, 2016 
SOUZA, P. M.; BRAGA, M. J. Aspectos Econômicos da Produção e Comercialização do Milho no Brasil. In: GALVÃO, J. C. C.; MIRANDA, G. V. Tecnologia de Produção do Milho. Viçosa: UFV, 2004. p. 13-52.

SILVA, E. C.; BUZETTI, S.; GUIMARÃES, G. L.; LAZARINI, E.; SÁ, M. E. Doses e épocas de aplicação de nitrogênio na cultura do milho em plantio direto sobre Latossolo Vermelho. Revista Brasileira de Ciência do Solo, Viçosa, v. 29, n. 3, p.353-362, 2005.

SILVA, O. C.; SCHIPANSKI, C. A. Manual de identificação e manejo de doenças do milho. Castro: Fundação ABC, 2006. 97 p.

SILVA, R. G.; GALVÃO, J. C. C.; MIRANDA, G. V.; SILVA, D. G.; ARNHOLD, E. Produtividade de milho em diferentes sistemas produtivos. Revista Verde, Mossoró, v. 2, n. 2, p.136-141, 2007.

VEZZANI, F. M.; CONCEIÇÃO, P. C.; MELO, N. A.; DIECKOW. J. Matéria orgânica e qualidade do solo. In: SANTOS, G. A.; SILVA, L. S.; CANELLAS, L. P.; CAMARGO, F. A. O. Fundamentos da matéria orgânica do solo: ecossistemas tropicais e subtropicais. 2. ed. Porto Alegre: Cinco Continentes, 2008. p. 483-494. 